\title{
Kansei Engineering Modelling for Packaging Design Chocolate Bar
}

\author{
Muhammad Amirul Ghiffari*, Taufik Djatna, Indah Yuliasih
}

Department of Agroindustrial Technology Bogor Agricultural University, Bogor, Indonesia

\begin{abstract}
Indonesia became the third largest cocoa producer in the world. However, the consumption of domestic chocolate is still very low. In order to increase the consumption of chocolate in Indonesia, we must improve all aspects related to chocolate. Manage the right business processes modeling can improve overall Small and Medium Enterprises (SME) performance. Business Process Modeling Notation (BPMN) is an efficient method aligning an organization with the wants and needs of the industry. Nowadays, chocolate bar production is packaged by simple SME with a visual display that isn't varied. To support customer preferences and build an identity that is embedded in the minds of the consumer, needs a comprehensive design-oriented consumer perspective. Kansei Engineering selected because it's able to connect the gap between industry and consumer. This study aims to improve consumer preferences in chocolate bar product. Hypotheses were carried out on various chocolate bar indicate that changes of visual appearance will increase the acceptance of consumer. The methodology in this study consisted of four steps: Need analysis and system modeling, identification element design process, find Kansei words and packaging design formulation. Data were collected by Term Frequency-Inverse Document Frequency (TF-IDF) and Quantification Theory Type (QTT) 1. The result of this research shows that the formulation of new packaging design with eye-catching strategy, make the color is red, the image is Milk, the typography is custom and the shape is attractive.
\end{abstract}

Keywords : Chocolate Bar, Kansei Engineering, Packaging Design

Author Correspondence:

Muhammad Amirul Ghiffari,

${ }^{1}$ Agroindustrial Technology Program Graduate School of Bogor Agricultural University,Bogor,Indonesia

E-mail: amirulelghiffari@gmail.com

\section{Introduction}

BPMN is a holistic management approach to improve business effectiveness and efficiency as it seeks to achieve innovation, flexibility, and integration with technology. BPMN can model complex messages that are passed between business persons or parts of businesses, events that cause messages to be missed, and business rules that limit the event. BPMN allows business processes to be mapped to an XML-based business execution language. One of the advantages of the BPMN diagram is the ability to model the flow of messages. Traditional business process diagrams are able to model the sequential flow of processes, from initial events to final results.

Kansei engineering is a method used to ensure that a product or service meets the desired emotional response [1]. This process makes it possible to model the customer's feelings or emotions and then translate them into the design parameters. In Japanese, Kansei means emotion. Emotions that are meant not only in terms of mind, but include vision, hearing, feeling, smell, taste, and cognition will be involved simultaneously. Kansei Engineering has an advantage over other similar methods, as it has the ability to translate the emotional needs of consumers into concrete design parameters through specific engineering techniques.

Packaging is an activity in the planning of goods that involves determining the design and 
manufacture of packaging for a product [2]. The packaging of food products serves as simple storage, maintenance, and protection for long periods of time. Therefore, the quality and handling cost of the food product is required. Generally the main purpose of packaging food products to maintain the quality or quality of products during distribution.

One of the most popular processed cocoa is the chocolate bar. Chocolate bars are popular among various circles because it has a distinctive taste and practical to consume. This should be made possible by the bar chocolate industry to increase productivity in order to accelerate the value of chocolate consumption in Indonesia. However, the facts on the ground are different. Chocolate bars produced by SMEs are often less consider the packaging aspect, so it is not able to convince consumers that their products are worth to be purchased. The challenges in the packaging industry show designers generate strongly about it and visualize the product in the form of simple and effective, leaving a positive perception to the consumer or buy other among similar products.

There were 4 main objectives in this research as follows: (a) Need Analysis and system modeling, Identification the design elements of packaging design, (c) identification packaging design on Kansei words and (d) formulate the new packaging design. In the future be required quantitative and qualitative formulation for the adaptive model of packaging design of the chocolate bar.

\section{Material and Methods}

In business, System Analysis and Design refers to the process of examining a business situation with the intent of improving it through better procedures and methods. System analysis and design relate to shaping organizations, improving performance and achieving objectives for profitability and growth [3]. The emphasis is on systems in action, the relationships among subsystems and their contribution to meeting a common goal. Looking at a system and determining how adequately it functions, the changes to be made and the quality of the output are parts of system analysis. With analysis and design, the production system that can improve the efficiency and effectiveness of the system especially in order to produce the packaging design of chocolate bar by using the Kansei engineering method was produced.

How to develop product design by identifying the product at an early phase. In this paper, we Identify design of chocolate bar in order to understand the design elements of chocolate bar product with collecting samples of chocolate bar product.

The synthesis process begins by conducting a survey of respondents using a semantic differential questionnaire to determine the weight of respondent's assessment the product elements obtained from the extraction of the word Kansei [4]. Synthesis process in this research was done to know the most important element which becomes the determinant of packaging design. The method used in extracting the word Kansei using the TF-IDF (Term Frequency - Inverse Document Frequency) method TF-IDF is a statistical method used to indicate the importance of data in a dataset. This is a way to print the importance of words (or "terms ") on the word Kansei based on how often the word appears in some questionnaires. The variants commonly used in this experiment are.

$\mathrm{wd}=\mathrm{w} \times \log (\mathrm{D} / \mathrm{w} \mathrm{D})$

$\mathrm{Wd}=$ Weighting from TF-IDF

$\mathrm{W}=$ Number of words in $\mathrm{d}$ data 
$D=$ Number of documents in the set of words

The design of the packaging element of the bar chocolate product can be analyzed using the product packaging that already exists on the market. This product packaging sample will be a reference in classifying packaging design elements based on the morphology of the packaging element form. Here are the steps in QT1 evaluation:

Step1: define the Kansei relational model associated with the Kansei measurement score of an experimental sample with respect to an image word pair. The categorical multiple regression models can be defined as:

$\hat{y}_{s}^{k}=\sum_{i=1}^{E} \sum_{j=1}^{c_{i}} \beta_{i j} x_{i j s}+\varepsilon$

$\hat{y}_{s}^{k}=$ the predicted value of criterion variable for the sth product sample on the kth image word.

I $\quad=$ the index of design element

$\mathrm{E} \quad=$ the number of design element

$\mathrm{J}=$ the index of category

$\mathrm{Ci}=$ the number of category of the ith design element

$\varepsilon=$ a stochastic variable whose expectation value $\mathrm{E}(\mathcal{E})=0$

$\mathrm{Bij}=$ the category score of the jth style within the ith design element

Xijs $\quad=$ the coefficient of the dummy variable

Step 2: calculate the standardized regression coefficients (4) and standardized constant in a model (5). The model of categorical multiple regression analysis can be redefined as (3):

$\hat{y}_{s}^{k}=\sum_{i=1}^{E} \sum_{j=1}^{c_{i}} \beta_{i j}^{*} x_{i j s}+\bar{y}_{s}^{k}$

$\beta_{i j}^{*}=\beta_{i j}-\frac{1}{n} \sum_{j=1}^{c_{i}} \beta_{i j}^{*} x_{i j s}$

$\bar{y}_{s}^{k}=\frac{1}{n} \sum_{j=1}^{c_{i}} y_{s}^{k}$

Step 3: Determine the matrix CCR of the correlation coefficient of all variables.

Step 4: Calculate the multiple correlation coefficients (R) that are regarded as the relational degree of external criterion variable and explanatory variables.

Step 5: Calculate the partial correlation coefficients (PCC) of design elements to clarify the relationships between product element and a product image.

Step 6: Determine the statistical range of categorical variable which indicates its contribution degree to the prediction model with respect to a given product.

\section{Result and Discussion}

\subsection{Need Analysis and System Modelling}

To analyze the existing system with Kansei engineering on the chocolate bar, we need to know what components are needed for the system to run. For the initial stage, know the inputs, outputs, and 
stakeholders who play a role in the system.

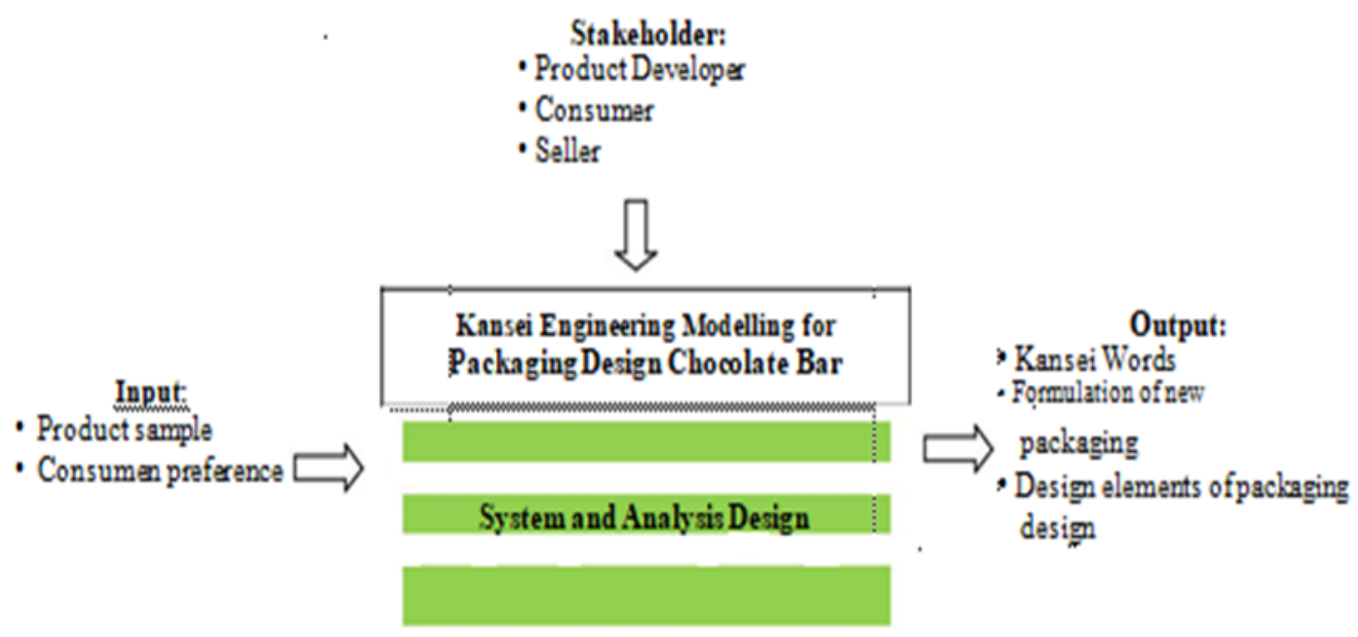

Figure 1

Need Analysis and System Modelling

Then BPMN represented that relationship between stakeholder, input, output and another aspect that determine the system. A process requires a sequence of business activities and supporting information. BPMN should be easy to understand to do a business analysis.

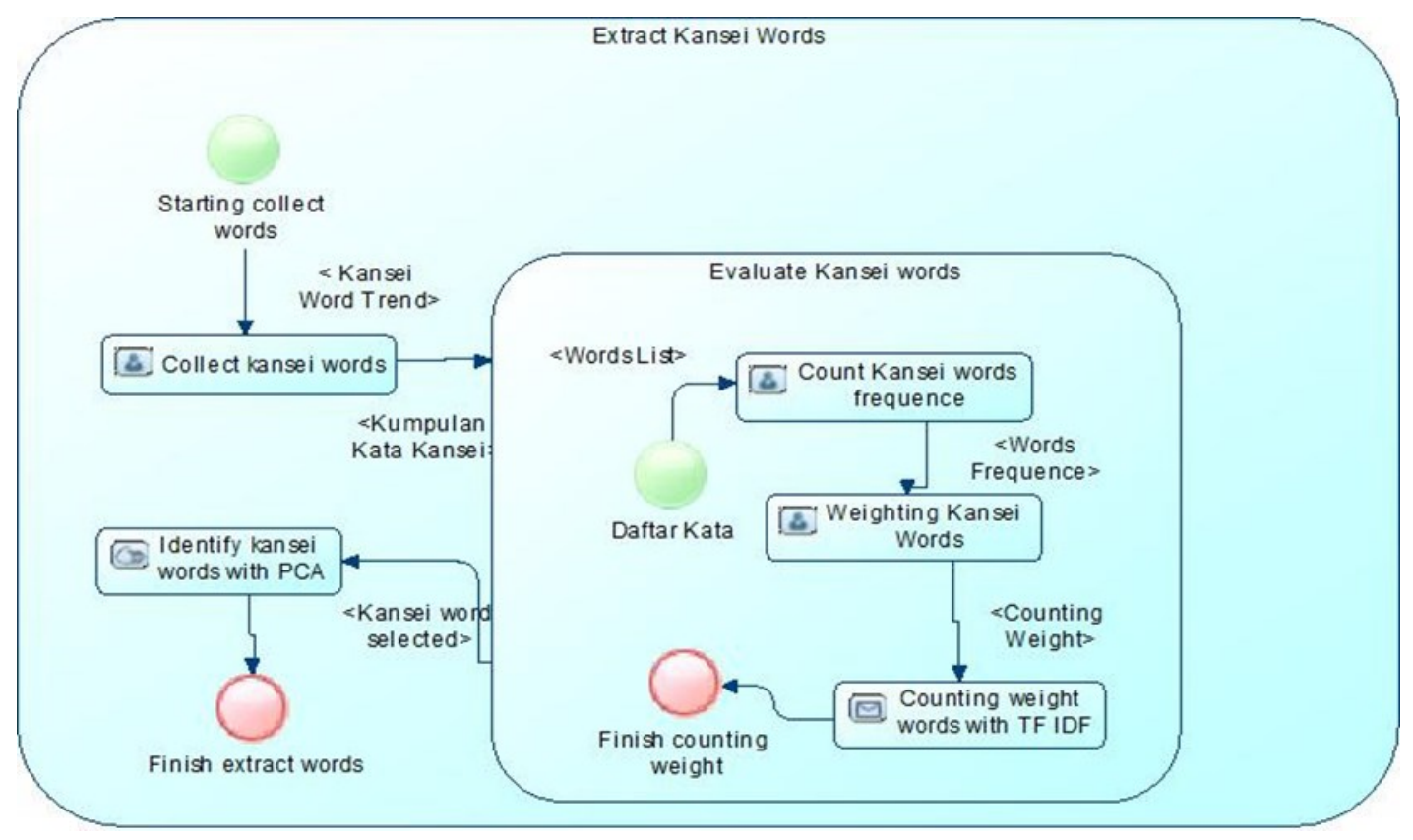

Figure 2

BPMN for identifying of design element packaging 


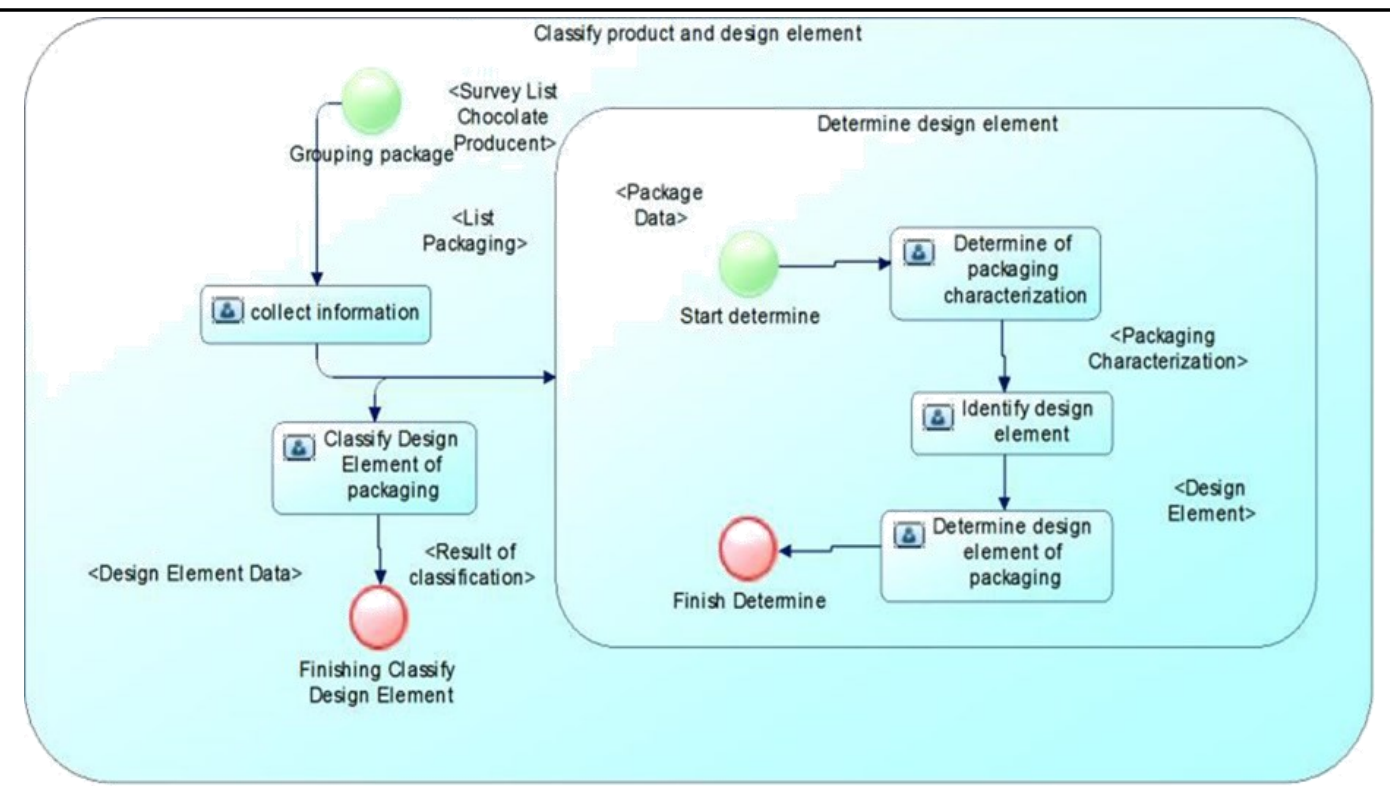

Figure 3

BPMN for Find Kansei words

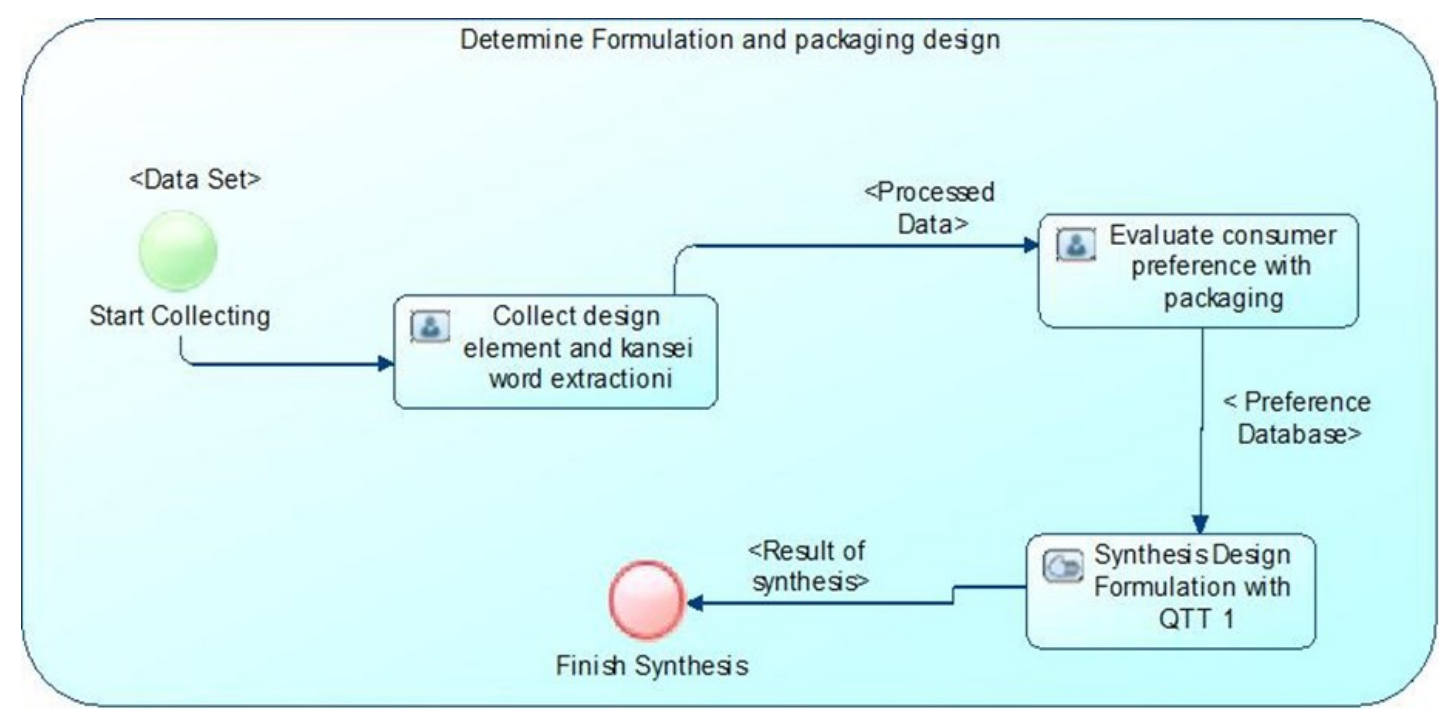

Figure 4

BPMN formulation packaging Design

\subsection{Packaging design element identification}

To identify the element design, we collect 10 samples of chocolate bar product. The result presented in Table 1. After identify, classify into the design element. The result presented in Table 2.

\subsection{Design elements on Kansei words}

The formulation use TF-IDF method on Kansei words analysis. Collected 8 questionnaires about Kansei words from consumers. In Table 3, there are the results of calculation Kansei words by using TF IDF from a hypothetical data of the questioner. The result is showing that the Kansei words that have the 
Kansei Engineering Modelling for Packaging Design Chocolate Bar

highest weight are "Communicative", "Traditional", "Elegant", "Eye-catching". From this result, the strategies for developing the packaging design of chocolate bar product was determined. Then this result was used for synthesis phase to get the formulation of packaging design of chocolate bar product.

Table 1

Identification of chocolate bar product

\begin{tabular}{llllll}
\hline Design & \multicolumn{5}{c}{ Type } \\
\cline { 2 - 6 } Element & $\mathbf{1}$ & $\mathbf{2}$ & $\mathbf{3}$ & $\mathbf{4}$ & Purple \\
\hline Color & Brown & Red & Blue & & \\
Image & Bar & Milk & - & - & Robust \\
Typography & Custom & Standard & - & - & \\
Shape & Attractive & - & - & & \\
\hline
\end{tabular}

Table 2

Classification of design element

\begin{tabular}{ccccc}
\hline Samples & $\mathbf{X 1}$ & $\mathbf{X 2}$ & $\mathbf{X 3}$ & $\mathbf{X} 4$ \\
\hline 1 & 3 & 1 & 2 & 2 \\
2 & 3 & 2 & 2 & 1 \\
3 & 3 & 3 & 1 & 1 \\
4 & 3 & 3 & 1 & 1 \\
5 & 1 & 2 & 1 & 1 \\
6 & 1 & 2 & 1 & 2 \\
7 & 1 & 1 & 3 & 1 \\
8 & 3 & 1 & 3 & 3 \\
9 & 3 & 2 & 3 & 3 \\
10 & 2 & 1 & 2 & 2 \\
\hline
\end{tabular}

Table 3

Result Calculation Words Using TF IDF

\begin{tabular}{llllllllll}
\hline & & & \multicolumn{7}{c}{ Dokumen } \\
\multicolumn{1}{l}{ Kansei Words d1 } & d2 & $\mathbf{d 3}$ & $\mathbf{d 4}$ & $\mathbf{d 5}$ & $\mathbf{d 6}$ & $\mathbf{d 7}$ & $\mathbf{d 8}$ & Wd \\
\hline Practical & 0 & 1 & 0 & 0 & 0 & 0 & 1 & 0 & 1,397940009 \\
Attractive & 0 & 0 & 0 & 0 & 1 & 0 & 1 & 1 & 1,568636236 \\
innovative & 0 & 0 & 0 & 0 & 0 & 1 & 1 & 0 & 1,397940009 \\
Eco-friendly & 1 & 1 & 1 & 1 & 1 & 1 & 0 & 1 & 1,084313720 \\
Communicative & $\mathbf{0}$ & $\mathbf{1}$ & $\mathbf{1}$ & $\mathbf{0}$ & $\mathbf{1}$ & $\mathbf{0}$ & $\mathbf{1}$ & $\mathbf{0}$ & $\mathbf{1 , 5 9 1 7 6 0 0 3 5}$ \\
Healthy & 0 & 1 & 0 & 0 & 0 & 0 & 1 & 1 & 1,568636236 \\
Safe & 0 & 1 & 0 & 1 & 1 & 0 & 0 & 0 & 1,568636236 \\
bright color & 0 & 1 & 1 & 1 & 0 & 1 & 1 & 0 & 1,505149978 \\
Traditional & $\mathbf{1}$ & $\mathbf{0}$ & $\mathbf{0}$ & $\mathbf{1}$ & $\mathbf{0}$ & $\mathbf{1}$ & 0 & 1 & $\mathbf{1 , 5 9 1 7 6 0 0 3 5}$ \\
luxurious & 1 & 1 & 1 & 1 & 1 & 0 & 1 & 1 & 1,331092498 \\
Elegant & $\mathbf{1}$ & $\mathbf{1}$ & $\mathbf{0}$ & $\mathbf{1}$ & $\mathbf{1}$ & $\mathbf{0}$ & $\mathbf{0}$ & $\mathbf{0}$ & $\mathbf{1 , 5 9 1 7 6 0 0 3 5}$ \\
natural & 1 & 1 & 1 & 0 & 1 & 1 & 1 & 1 & 1,08431372 \\
high quality & 0 & 1 & 0 & 0 & 0 & 0 & 1 & 1 & 1,568636236 \\
Eye catching & $\mathbf{1}$ & $\mathbf{0}$ & $\mathbf{0}$ & $\mathbf{0}$ & $\mathbf{1}$ & $\mathbf{0}$ & $\mathbf{1}$ & $\mathbf{1}$ & $\mathbf{1 , 5 9 1 7 6 0 0 3 5}$ \\
\hline
\end{tabular}




\subsection{Packaging Design Formulation}

Table 4

Evaluating packaging design

\begin{tabular}{lllllcccc}
\hline No & & & & & Communicative- & \multicolumn{3}{c}{ Traditional elegant-not Eye Catching - } \\
\cline { 6 - 9 } samples & X1 & X2 & X3 & X4 & Passive & - modern & elegant & Unsightly \\
\hline 1 & 1 & 2 & 3 & 3 & 2.9 & 6.9 & 6.1 & 2.1 \\
2 & 1 & 1 & 2 & 3 & 4.5 & 5.3 & 4.6 & 2.1 \\
3 & 2 & 1 & 1 & 1 & 6.2 & 4.6 & 6.8 & 6.8 \\
4 & 1 & 1 & 1 & 2 & 6.4 & 5.4 & 5.4 & 4.9 \\
5 & 3 & 3 & 1 & 3 & 6.9 & 6.5 & 3.9 & 3.3 \\
6 & 2 & 3 & 1 & 1 & 5.9 & 2.3 & 5.6 & 5.4 \\
7 & 3 & 1 & 1 & 1 & 5.4 & 5.4 & 2.5 & 4.6 \\
8 & 3 & 1 & 3 & 1 & 4.0 & 3.6 & 6.5 & 2.1 \\
9 & 1 & 1 & 1 & 3 & 5.7 & 5.6 & 6.9 & 4.1 \\
10 & 1 & 2 & 1 & 1 & 2.2 & 6.3 & 2.5 & 6.7 \\
\hline
\end{tabular}

Table 5

The result of QTT 1 analysis

\begin{tabular}{|c|c|c|c|c|c|c|c|c|c|}
\hline Decion & & C-P & & TRD-MD & & E-NE & & EC-US & \\
\hline Element & & $\begin{array}{l}\text { Category } \\
\text { score }\end{array}$ & PCC & $\begin{array}{l}\text { Category } \\
\text { score }\end{array}$ & PCC & $\begin{array}{l}\text { Category } \\
\text { score }\end{array}$ & PCC & $\begin{array}{l}\text { Category } \\
\text { score }\end{array}$ & PCC \\
\hline \multirow[t]{3}{*}{$\overline{X 1}$} & X11 & -0.973 & 0.823 & -1.23 & & 0.67 & & -0.278 & \\
\hline & $\mathrm{X} 12$ & 1.507 & & 0.57 & 0.407 & 1.37 & 0.65 & 1.202 & 0.91 \\
\hline & $\mathrm{X} 13$ & 0.617 & & 1.67 & & -2.03 & & -0.338 & \\
\hline \multirow[t]{3}{*}{$\mathrm{X} 2$} & $\mathrm{X} 21$ & 0.376 & & -0.28 & & 0.84 & & -0.084 & \\
\hline & $\mathrm{X} 22$ & -1.144 & & 3.22 & & -2.76 & & 1.296 & \\
\hline & $\mathrm{X} 23$ & 0.016 & 0.343 & -2.38 & 0.713 & 0.24 & 0.73 & -1.044 & 0.94 \\
\hline \multirow[t]{3}{*}{$\mathrm{X} 3$} & X31 & 0.382 & & 0.45 & & -0.39 & & 0.832 & \\
\hline & X32 & -0.818 & & 0.15 & & -2.69 & & -1.168 & \\
\hline & X33 & -0.928 & 0.562 & -1.65 & 0.446 & 2.71 & 0.97 & -2.328 & 0.72 \\
\hline \multirow[t]{3}{*}{$\mathrm{X} 4$} & X41 & -1.045 & 0.612 & -1.43 & 0.381 & -0.40 & 0.88 & 0.420 & 0.88 \\
\hline & $\mathrm{X} 42$ & 1.605 & & 1.27 & & -0.80 & & 0.220 & \\
\hline & $\mathrm{X} 43$ & 0.905 & & 1.47 & & 0.70 & & -0.580 & \\
\hline $\mathrm{R}$ & & 0.9563 & 0 & 0.9282 & 0 & 0.6712 & 0 & 0.8506 & 0 \\
\hline $\mathrm{R} 2$ & & 0.9396 & 0 & 0.9642 & 0 & 0.9635 & 0 & 0.9834 & 0 \\
\hline
\end{tabular}

Table 6

Design of new packaging design

\begin{tabular}{lllll}
\hline Design Element & X1 & X2 & X3 & X4 \\
\cline { 2 - 5 } & Color & Image & Typography & Shape \\
\hline Communicative & Red & Bar & Custom & Robust \\
Passive & Brown & Milk & Standard & Attractive \\
Traditional & Blue & Milk & Custom & Robust \\
Modern & Red & Bar & Standard & Attractive \\
Elegant & Red & Bar & Standard & Robust \\
Not Elegant & Blue & Milk & Custom & Attractive \\
Eye-Catching & Red & Milk & Custom & Attractive \\
Unsightly & Blue & Bar & Standard & Robust \\
\hline
\end{tabular}




\section{Conclusion}

The design of the chocolate bar packaging on Kansei's words is divided into four categories: communicative, traditional, elegant and eye-catching. Finally, the formulation of the new packaging design of chocolate bar was obtained by using KE where the design of the chocolate bar packaging with the eye-catching strategy has the highest R2 so that it fits. For statistical models, it is very important and recommended. To realize this design with red, illustrated milk, with typography that is adjusted and has an attractive shape.

\section{Acknowledgments}

Thank you to all the friends who helped me in my research, to my supervisor and lecturers. We also thank the family who always helps me in prayer.

\section{References}

[1] Nagamachi, M. (2010). Kansei Engineering: Kansei / Affective Engineering (Industrial Innovation). CRC Press

[2] Calver, G. (2004). What Is Packaging Design, Roto Vision SA

[3] Jedlicka, W. (2009). Packaging Sustainability Tools, Systems, and Strategies for Innovative Package Design. The USA, John Wiley, and sons.

[4] Nagamachi, M. (2008). Perspectives and a new trend of Kansei/Affective Engineering. TQM Journal 